\title{
A FORMAÇÃO DO PROFISSIONAL DA INFORMAÇÃO RELACIONADA ÀS TECNOLOGIAS DE INFORMAÇÃ̃O: OS BIBLIOTECÁRIOS NA PERSPECTIVA DA LITERATURA, REFLEXÕES.
} PROFESSIONAL FORMATION OF THE INFORMATION PROFESSIONALS: LIBRARIANS IN LITERATURE, REFLEXIONS

Maria Tereza Machado Teles Walter, Mestre Doutoranda em Ciência da Informação, UnB Membro do Grupo de Pesquisa sobre Formação Profissional e Mercado de Trabalho mtmtwalter@terra.com.br

\begin{abstract}
RESUMO
A maciça introdução das tecnologias de informação e de comunicação no contexto de trabalho dos profissionais da informação redundou em modificações na forma de atuar, nas perspectivas de fornecimento de informações e geração de produtos e serviços para os usuários e nas necessidades de formação e educação. Esse trabalho aborda alguns pontos relativos às dificuldades do equacionamento das disciplinas de conteúdo tecnológico no processo de formação dos bibliotecários e como essas questões têm sido observadas na literatura. Discute-se, também, as zonas de interface com outros segmentos profissionais e quanto se deve garantir de características distintivas de forma a manter a competitividade profissional dos bibliotecários no mercado de trabalho.
\end{abstract}

PALAVRAS-CHAVE: Profissional da informação. Bibliotecário. Formação profissional. Tecnologia de informação.

\section{INTRODUÇÃO}

A escrita é, acima de tudo,

[...] um procedimento do qual atualmente nos servimos para imobilizar, para fixar a linguagem articulada, por essência fugidia. Diante de sua necessidade de um meio de expressão permanente, o homem primitivo recorreu a engenhosos arranjos de objetos simbólicos ou a sinais materiais, nós, entalhes, desenhos. Em nossos dias, a reprodução em disco ou fita magnética, outro procedimento de fixação da linguagem, mais direto que a escrita, começa a concorrer com ela.

Assim inicia Charles Higounet (2003, p.9) seu livro sobre a "História concisa da escrita". E ele prossegue dizendo que "contudo, a escrita é mais que um instrumento. Mesmo emudecendo a palavra, ela não apenas a guarda, ela realiza o pensamento que até então permanece em estado de possibilidade".

Se entendermos a escrita como uma das primeiras formas de tecnologia de comunicação, expressão e registro da informação, pode-se sugerir que com o passar do tempo, em função da massa documental e das premências de recuperação para diversos fins, 
inevitável seria o desenvolvimento de formas e métodos mais eficientes e robustos para "realizar o pensamento" e torná-lo mais que possibilidade.

Man (2004, p.11), na introdução do livro que trata da invenção de Gutenberg, ajuda a entender o significado e a importância dessas etapas, sem a necessidade de percorrer os séculos entre os primórdios dos registros humanos e a tecnologia, como a utilizamos nesse início de século XXI. Diz ele que "Em um gráfico da comunicação humana nos últimos cinco mil anos, a curva ascendente que vai do grunhido ao correio eletrônico não é regular. Tem quatro pontos principais, cada um marcando momentos nos quais a comunicação atingia um novo nível de velocidade e alcance". Segundo o autor, o primeiro foi a invenção da escrita, o segundo a invenção do alfabeto, o terceiro (objeto de seu livro) foi a invenção da imprensa com tipos móveis e o quarto que "parece estar nos transformando em células de um cérebro planetário", que é o advento da internet.

É no contexto desse tempo, cuja velocidade de mudanças nem pode mais ser considerado novo, que situamos este estudo. A partir da definição de tecnologias de informação e de comunicação, extraída de Takahashi (2000), de que são aquelas utilizadas para tratamento, organização e disseminação de informações, são analisados alguns aspectos acerca da atuação profissional dos profissionais da informação, especialmente dos bibliotecários, focalizando o impacto que causaram na sua formação e quais as tendências que se percebe na literatura sobre esse tema.

Não se concebe o trabalho com a informação, em seus múltiplos aspectos, sem a utilização das tecnologias de informação. Isso é fato indiscutível e não parece ser mais item de controvérsia na preparação de profissionais que atuam na área. Os textos que tratam de formação profissional para atuar em serviços ou sistemas de informação têm em comum o fato de recomendarem fortemente o conhecimento e capacitação para utilização dessas tecnologias. As diferenças situam-se muito mais no aspecto focalizado pelos diferentes autores que podem tratar mais de questões relacionadas com a habilidade de utilização e manipulação dessas tecnologias, enquanto outros centram suas preocupações na capacitação para a construção de conteúdos utilizando as diferentes plataformas ou sistemas ou recursos disponíveis.

Há outros pontos igualmente importantes que dizem respeito à competência necessária no processo de seleção da melhor tecnologia a ser adotada por um serviço ou em um sistema de informação, à destreza na manipulação de conteúdos potenciais que podem ser gerados, sensibilidade para identificar nichos potenciais de atuação e atenção para acompanhar as evoluções que nesse ambiente são de uma agilidade às vezes asfixiante. 
A descrição dessas características de perfil profissional profundamente afetado pelo ambiente tecnológico existe em todas as áreas, mas, na de informação, ocupa um papel estratégico, o que pode ser avassalador e esmagador sob certos aspectos. A entrada das tecnologias de informação foi muito mais rápida que a possibilidade de preparação dos profissionais que já estavam no mercado de trabalho e, por outro lado, implicou na modificação dos currículos nas universidades, favorecendo o conhecimento da manipulação das ferramentas, cujos resultados, longo prazo, merecem e devem ser acompanhados.

No livro sobre o profissional do século XXI, Hamilton Werneck (2003) relaciona diversos aspectos que devem ser desenvolvidos nos indivíduos, de forma a torná-los não apenas competitivos, reduzindo-os às questões mercadológicas, mas seres integrais, que tenham sensibilidade, modernidade, criatividade e saibam relacionar-se em ambientes tão hostis.

\section{REVISÃO CRÍTICA DA LITERATURA}

Discute-se, no presente trabalho, o que a literatura tem apresentado sobre o tema de formação profissional para os profissionais da informação, enfocando, especificamente a questão das tecnologias de informação, especialmente no que tange aos bibliotecários.

\subsection{Bibliotecário e profissional da informação}

Os estudos sobre a profissão bibliotecária não são novos e suas habilidades, competências e características têm sido debatidas ao longo do tempo sob diversos ângulos.

Resgatando Ortega y Gasset (1965, p.26) sobre a missão profissional, ele inicia sua análise com uma interessante constatação que trata do significado entre o homem e seu trabalho (quehacer), pois, afirma ele, para viver temos sempre que estar fazendo algo, sob pena de sucumbir. E o fazer bibliotecário, a missão profissional, conforme Ortega y Gasset, parte não do

[...] homem que a exerce, de seus gostos, curiosidades ou conveniências, nem tampouco de um ideal abstrato que se pretende definir de uma vez por todas acerca do que é uma biblioteca, mas sim da necessidade social que a profissão serve. E esta necessidade, como tudo que é propriamente humano, não consiste em uma magnitude fixa, pois é por essência variável, migratória, evolutiva, em suma, histórica.

Se as profissões se desenvolvem como uma resposta às necessidades sociais, então, e a sociedade é variável, migratória e evolutiva, a angústia e tom catastrófico que permeiam os textos que tratam da formação profissional dos bibliotecários não teriam razão de ser. 
Deveriam, em verdade, considerar a mudança como parte intrínseca de qualquer atividade humana. Evidentemente não é possível desconsiderar que algumas profissões tornaram-se obsoletas e desnecessárias à sociedade ao longo da história da humanidade, como, por exemplo, a dos copistas, mas pode-se olhar por outro prisma e refletir não sobre extinção, mas a respeito de modificação de modos de fazer.

O delineamento profissional a partir de desejos sociais, por outro lado, é complexo pois há inúmeras variáveis que interferem nessa delimitação. São diversos estratos, carências, perspectivas, possibilidades, sonhos, premências, consciências, acessos, além de recursos diversos requeridos que inviabilizam a compreensão de uma sociedade como unidade. Não é novidade a utilização de Brasis para distinguir as evidentes diferenças encontradas em todos os níveis no país. Adicione-se a isso a comparação com outros países, culturas e ambientes tecnológicos e obtém-se um quadro realmente amplo para inserir uma categoria profissional como a dos bibliotecários, cuja missão tradicional confunde-se mais com os livros que com a informação, essa última um segmento mais amplo, mais fluido e mais complexo de trabalho.

Segundo Abbott (1988, p.215), a história do sistema das profissões inicia-se com um distúrbio que pode ser uma nova tecnologia requerendo julgamento profissional ou uma nova técnica para um trabalho profissional antigo. Estes distúrbios, então, determinariam novos rearranjos.

Para facilitar a análise dos textos que tratam da profissão bibliotecária emprestamos de Mueller (1989) o entendimento a respeito de perfil profissional, como sendo o "conjunto de conhecimentos, qualidades e competências próprias dos integrantes de uma profissão", conceito que está ligado à questão de desempenho da função profissional, segundo ela. Em seu trabalho a autora reconhece que a discussão do perfil passa, necessariamente, pela formação profissional e que historicamente os bibliotecários são reconhecidos por algumas funções, especialmente:

- função da preservação;

- função da educação;

- função do suporte ao estudo e à pesquisa.

Fica evidenciada, também, no mesmo documento, a preocupação com o atendimento às necessidades de informação das pessoas, que permeia todas essas funções. Esse parâmetro básico que considera o usuário (ou cliente como preferem aqueles que trabalham em consonância com as teorias da qualidade) como primeiro beneficiário do fazer bibliotecário é 
encontrado também nas velhas (e constantemente renovadas e revisitadas) "leis da biblioteconomia" de Ranganathan (apud Campos, 200?):

- os livros são para usar;

- a cada leitor seu livro;

- a cada livro seu leitor;

- poupe o tempo do leitor;

- a biblioteca é um organismo em crescimento.

Que em última instância é uma confirmação da visão de Ortega y Gasset (1965) de encarar as organizações que trabalham com informação como organismos em mutação, assim como as profissões, assim como a vida.

A evolução da área, que passou de Biblioteconomia e trabalho fundamentalmente ligado aos suportes tradicionais da informação - livros e periódicos - para Ciência da Informação - com espectro de atuação amplificado, além da maciça introdução das tecnologias de informação - foi outro aspecto que determinou novos ângulos no olhar e na formação dos bibliotecários. Essas mudanças não têm sido feitas de maneira suave, mas marcadamente dura com relação à análise e avaliação dos bibliotecários, iniciando pela proposição da alteração da nomenclatura para profissional da informação, como se esse fato fosse determinante para o nascimento de um novo modo de fazer.

A história da profissão bibliotecária é bem descrita em Thompson (1977) que traça suas origens desde o Egito e passa pelas transformações em sua importância social e pela forma de oferecer seu trabalho ao longo do tempo. De personagem estratégico na manutenção do poder, pessoa culta e que dominava diferentes saberes e idiomas, o tempo e as transformações das bibliotecas em instituições públicas foram decisivos, segundo o autor para essa modificação de status e de modo de atuar. A análise histórica feita por Thompson é interessante e merece ser conhecida pela forma um tanto irônica que trata do assunto. Também ele reconhece as funções de educação e de preservação e identifica a transformação de "ocupação" em profissão, requerendo treinamento e educação profissional.

Em relação ao Brasil, há vários estudos sobre o ensino de Biblioteconomia no país, incluindo o de Castro (2000, p.23), que utiliza a definição de Población que reconhece quatro fases distintas:

[...] formação humanista (1915-1928); pragmatismo americano (1929-1969); ufanismo nacionalista caracterizado pelo crescimento qualitativo [sic] (quantitativo) das escolas (19701985); estabilização do crescimento quantitativo das escolas e início do período de reflexão, objetivando a avaliação qualitativa do ensino ministrado em nível de graduação (1986- ). 
Esses cortes refletem, provavelmente, a evolução da formação profissional dos bibliotecários em relação às demandas e necessidades dos mercados e decorrentes do uso maciço das tecnologias no cotidiano dos serviços e sistemas de informação.

Mais recentemente, os textos que estudam os bibliotecários incluíram outros pontos, que se referem à relação dessa categoria com outros perfis como, por exemplo, o de Marchiori (1996) em que é abordada a interface das diferentes formações, especialmente dos bibliotecários, dos arquivistas, dos jornalistas e dos egressos do curso de processamento de dados, como partes atuantes e integrantes do grupo profissional que poderia receber a denominação de profissional da informação.

Os documentos que tratam da interligação, da conexão e da superposição de diversas áreas têm sido a tônica dos estudos sobre os bibliotecários, adicionando-se, também, as demandas advindas da sociedade da informação, em cujo mundo competitivo e ágil estes deverão atuar. Outro olhar interessante é o de Blattmann (1999), que em seu trabalho sobre os "Bibliotecários na sociedade da informação" coloca outro item que merece reflexão e que trata do processo de mudança - de postura, de funções, de habilidades e de desempenho que, segundo ela, somente ocorre quando há consciência de insatisfação pessoal ou institucional.

É difícil encontrar nos textos atuais uma referência aos bibliotecários e seu modo de atuar, que não seja crítica e que não denigra, de algum modo, a forma como executa suas atividades, seu apego a valores "antigos", sua "fixação" em normas e padrões, sua desatenção com as tecnologias e todos esses questionamentos que são comuns e em certo sentido estereotipados. É igualmente cada vez mais raro um texto que não exclua essa categoria profissional e apenas trate do "moderno profissional da informação" (Guimarães, 1997) servindo os bibliotecários apenas como paradigma de como não se deve trabalhar em relação à informação.

As habilidades normalmente relacionadas como necessárias aos profissionais da informação denotam a preocupação com a utilização das tecnologias de informação como fator determinante para o sucesso, além de outras competências que incluem a capacidade de captar e tratar informação estratégica, capacidade de síntese, aptidão para o trabalho em equipes multidisciplinares, entre outras.

Em texto que discute o impacto das tecnologias no trabalho bibliotecário, Braun (2002) mostra que a introdução das tecnologias de informação revolucionou de fato o trabalho nas bibliotecas. Segundo ela, as equipes das bibliotecas devem estar treinadas e aptas a 
utilizar e a prover informação tanto da forma impressa quanto em formatos digitais. Essa discussão sobre a formação profissional dos bibliotecários não é doméstica e afeta todos os países, como relata Bednarek-Michalska (2002), no caso da Polônia. Permeando esse tema está o fato de as tecnologias de informação terem definitivamente alterado o modo de atuar e as perspectivas profissionais em todas as áreas de trabalho.

Mas não se trata apenas de utilizar as ferramentas para buscar informação ou para organizá-la. É possível vislumbrar outras realidades como a produção de informação para os usuários nas intranets ou internet; construir informação ou rearranjá-la em formatos e conteúdos antes restritos aos autores primários; intermediar a informação em tempo real - de fato! Além disso, não se deve perder a noção de que alguns serviços tradicionais nas organizações já estão sofrendo os impactos não apenas das tecnologias propriamente ditas, mas também dos conteúdos disponíveis na web e que estão revolucionando outros aspectos como as questões de acessibilidade, de relacionamento entre bibliotecários e usuários, do questionamento da real necessidade de bases referenciais diante da oferta de bases de dados que contêm textos integrais, dos serviços de atendimento presenciais em relação aos virtuais, além da evidente mudança de eixo de atuação profissional em alguns segmentos, como, por exemplo, o de tratamento da informação.

E, recorrentemente, somos impelidos a constatar nossa quase incapacidade de acompanhar o ritmo vertiginoso das mudanças. Alheamo-nos, em muitos casos, divergimos da realidade, reforçamos comportamentos e alimentamos a literatura com fartos casos de dificuldades de modernização de organizações muitas vezes em função da deficiência de formação do pessoal.

Guimarães (2004, p.91-92) refletindo sobre a formação profissional no, conforme sua denominação, "ambiente educativo da área de informação", identifica, no caso brasileiro, duas dimensões que são: o conjunto de fazeres "ligados à ambiência, como é o caso do arquivo e da biblioteca" e "conjuntos de processos que atuariam em dois níveis", sendo um a do documento materialmente considerado e outro da informação como conjunto de estruturas significantes com capacidade de gerar conhecimento para o indivíduo e para a sociedade.

Decorrente da maciça introdução das tecnologias da informação é perceptível a mudança do foco de discussão dos bibliotecários para os denominados profissionais da informação, que abarcariam gama maior de perfis, inclusive dos pós-graduados em ciência da informação. E tratar da formação desse grupo é tarefa ainda mais árdua, por sua fronteira ser de delimitação mais difusa. 
Smit e Barreto (2002), falam sobre essa dificuldade em virtude de, no Brasil, a prática profissional ser ancorada numa tradição biblioteconômica que, segundo eles, tende a justificar seu trabalho mais pelas técnicas que pelos objetivos sociais perseguidos, além da fragilidade da definição do objeto da área do conhecimento da ciência da informação, que ainda não dispõe de um conceito consolidado.

De todo modo, independentemente da denominação utilizada, do contexto de atuação ou mesmo do país em que trabalham os genericamente denominados profissionais da informação, grupo que inexoravelmente os bibliotecários integram, o fato é que as tecnologias de informação revolucionaram as possibilidades de atuação profissional e aparentemente muitos segmentos ainda não perceberam isso de forma clara. Embora utilizem essas tecnologias de informação em seu cotidiano de atividades, fazem-no de maneira básica, sem esgotar nem mesmo as mais simples possibilidades dos sistemas que dispõem. E se isso é um problema atual, será maior com a passagem do tempo e com o ingresso de novas gerações de profissionais que nasceram após a introdução das diferentes mídias, formatos e sistemas de informação e que cresceram sem o drama da absorção de tecnologia, sem receios e sem bloqueios na exploração dos recursos.

Entretanto, o impacto da tecnologia sobre a atividade profissional relacionada à informação carece ser acompanhado e avaliado e se efetivamente as novas gerações profissionais são mais eficazes por dominá-las ou se uma formação humanista paralela também ainda encontra espaço. Não se trata absolutamente de confronto em termos de quem é melhor, mas de uma espécie de combinação de diferenças, que podem se reverter em melhores formas de agir e pensar a profissão.

\subsection{Tecnologia da informação}

As tecnologias de informação e comunicação são definidas por Takahashi (2000) como compreendendo o conjunto de sistemas e equipamentos que são utilizados para tratamento, organização e disseminação de informações. Embora possa ser considerada simplista em sua síntese desse mundo tecnológico, que tem revolucionado praticamente todas as áreas técnico-científicas e mesmo fora do âmbito das organizações de pesquisa e as acadêmicas, os resultados $\mathrm{e}$ as possibilidades que oferecem são ainda repletos de especulações.

Pensar em tendências ou mesmo tentar prever cenários a partir das aplicações ou dos estudos nessa área é tarefa complexa. Mesmo considerando a juventude da web, sua esfera de influência para a sociedade é impressionante. Dela já podem ser extraídas algumas respostas 
para as demandas sociais de acesso e acessibilidade à informação cujos milhões de páginas e de serviços dinamitaram fronteiras, encurtaram distâncias e ampliaram as formas de comunicação e troca, mesmo levando-se em consideração os países em desenvolvimento, como o Brasil, em que essa ainda é uma área restrita àqueles que dispõem de formas de acesso à rede.

Se a escrita permitiu o registro das experiências e com isso fazer avançar o conhecimento, as tecnologias de informação alargaram de maneira incalculável esses contornos. A globalização é um reflexo dessas tecnologias pois, sem elas, eventos que interferem nas diversas sociedades independentemente de quão distantes elas são não ocorreriam, especialmente na velocidade com que acontecem.

Barros (2001, p.74) coloca esse ponto de maneira bastante clara quando diz que:

Os estudos que buscam caracterizar e analisar as transformações por que passam as sociedades contemporâneas tomam, geralmente, como ponto de partida os avanços científico-tecnológicos ocorridos na segunda metade do século XX. Isso porque na base explicativa desse processo histórico está evidente o papel fundamental de um novo paradigma tecnológico organizado sobretudo em torno da tecnologia da informação.

As aplicações das tecnologias de informação são múltiplas e perpassam as diferentes áreas do conhecimento. Não se pode falar em seqüenciamento genético sem ligá-lo inexoravelmente a hardwares e softwares, pois se a idéia já existia antes, sua consecução só foi possível em ambientes de tecnologia de processamento eletrônico de dados bastante robustos.

No campo da ciência da informação não é novidade reconhecer que as tecnologias de informação exercem um papel preponderante em todas as rotinas de qualquer atividade que se possa imaginar nas bibliotecas, nos centros e serviços de informação. Integram todos os processos, desde o planejamento, incluindo a interface com clientes dos serviços, que se tornam igualmente remotos em função das possibilidades de comunicação, até trabalhos mais administrativos, como o empréstimo de material bibliográfico.

Embora tenha sempre absorvido de maneira bastante evidente as tecnologias que se apresentam, é interessante lembrar as palavras de Barbosa (1998, p.53):

\footnotetext{
No momento em que se procura mensurar a crescente importância dos setores produtivos que lidam com a informação, em que se observa a contínua introdução das novas tecnologias de informação e se constata o desenvolvimento de [...] campos de informação irmãos (processamento de dados, sistemas de informação, ciência da computação, ciência da informação, inteligência artificial, multimídia etc.), é irônico observar que o papel das bibliotecas e dos bibliotecários esteja recentemente sendo colocado em xeque.
}

A Ciência da Informação encontra nas tecnologias de informação o suporte indispensável de sua vertente pragmática. Os paradigmas de desenvolvimento e prestação de 
serviços alteraram-se drasticamente com o uso fundamental das bases de dados, dos acessos remotos, de sistemas de comunicação e de informação que modificaram substancialmente a relação usuários/acesso à informação. Mesmo não tendo solucionado todas as questões relacionadas com a recuperação de informação, os sistemas, indubitavelmente, enriqueceram as possibilidades de registro e de construção de expressões de pesquisa; tornaram mais importantes os questionamentos quanto à melhor forma de tratamento das informações; evidenciaram as dificuldades de controle da produção intelectual, agora em multimídia, conseqüentemente, multiplicada em termos de volume de informações, de fontes e de organização; e romperam a fronteira de necessidades de informação do campo técnicocientífico para as demandas particulares por informação.

Diante da complexidade dos temas que se originam a partir do advento das tecnologias de informação e de comunicação, observa-se que os documentos que tratam dessas aplicações apresentam abordagens em geral otimistas, plenas de soluções e de perspectivas positivas. Raramente são apresentados problemas nos textos que falam de processos e procedimentos na adoção de novos produtos e as tecnologias são valorizadas às vezes em detrimento dos conteúdos e das necessidades dos usuários.

Se por um lado essa apresentação é instigante, pelo estímulo à adoção de sistemas de informação e às pesquisas, por outro cria uma legião de seguidores quase fanáticos de sistemas cuja vida útil é reduzida pelo mercado que apresenta outras opções mais modernas e funcionais; ou mesmo por utilitários novos, que pouca importância dão ao cuidado que se tem que ter na seleção das soluções corporativas; e que suavizam a questão do custo, item quase nunca mencionado e muito menos dimensionado de forma real e concreta.

Tratando exatamente desse tema que é espinhoso e cujas conseqüências por seleções equivocadas significa um alto custo para a organização, Rezende (2002) analisa a adoção das tecnologias de informação como um recurso estratégico e que requer planejamento análise e sobretudo muita reflexão. De acordo com o autor, o contexto do mundo globalizado reforçou o papel das tecnologias de informação como facilitadoras nos processos de organização de conhecimentos e fornecimento de informações oportunas, mas, para que os objetivos da organização sejam atingidos, os recursos investidos nas tecnologias devem ser estudados e desenvolvidos no mesmo direcionamento, buscando, conforme suas palavras, o alinhamento entre o planejamento estratégico e a tecnologia de informação.

No processo de formação profissional, relacionado às tecnologias de informação, é difícil imaginar que os conteúdos dos cursos não sejam modificados constantemente em função da emergência de novas soluções e aplicações. Um exemplo disso pode ser observado 
em Bio, que em 1994 publicou um livro sobre sistemas de informação sob enfoque gerencial. Em capítulo que tratava dos impactos do processamento eletrônico de dados nos sistemas de informação, segundo ele, havia excessiva concentração na necessidade de domínio da tecnologia e pouca atenção para questões como: para que e porque fazer?

Dez anos depois o discurso já é outro e os conteúdos adquiriram maior destaque no tocante às discussões tecnológicas. A definição de Boar $(2002$, p.2) já é bem mais ampla, conforme pode ser verificado:

A tecnologia da informação é a preparação, coleta, transporte, recuperação, armazenamento, acesso, apresentação e transformação de informações em todas as suas formas (voz, gráficos, texto, vídeo e imagem). A movimentação de informação pode ocorrer entre seres humanos, entre humanos e máquina e/ou entre máquinas. $\mathrm{O}$ gerenciamento da informação garante seleção, distribuição, administração, operação, manutenção e evolução dos bens de tecnologia da informação de forma coerente com as metas e objetivos da organização.

Bertholino (1999) é outro estudo que apresenta algumas considerações sobre utilização de tecnologia de informação concomitantemente com os suportes tradicionais, sem, entretanto, negar que percebe uma tendência de os suportes eletrônicos cada vez mais se tornarem fontes principais. No caso específico da pesquisa tratava-se igualmente de identificar as novas formas de atuação das bibliotecas e sua inexorável migração para os ambientes digitais. Em seu texto a autora, citando Lancaster, enumera algumas modificações do cenário das bibliotecas dos quais destacam-se: bibliotecas serão centros de permuta, mas construirão índices e outras ferramentas para facilitar o acesso aos recursos da rede; bibliotecas alcançarão importantes funções na construção de bases de dados, criando novas informações compostas e possivelmente em algumas atividades de publicações eletrônicas.

Que as tecnologias de informação estão estreitamente relacionadas às diversas atividades humanas é evidente. Para estudar o tema do presente trabalho, por exemplo, foram utilizados diferentes fontes e suportes de informação: das tradicionais impressas, livros e artigos de periódicos, aos bancos de dados. E as dificuldades relacionadas com o volume de informações também são concretas. Uma busca simples efetuada na Science Direct Online, utilizando as palavras-chave "information technology" recuperou aproximadamente 10.000 referências de conteúdos disponíveis nos 1.600 títulos de periódicos que compõem o acervo desta base. Refinando a busca com os termos "information science", houve uma redução para quase 800 referências. Fazendo um exame rápido e superficial pôde-se identificar que os textos continham desde o estudo teórico sobre as tecnologias, até as aplicações diversas reais ou imaginadas, passando pelos estudos de futurologia.

O que vale destacar, nesse sentido, é que o campo de aplicação das tecnologias é bastante amplo, e que a formação profissional dos bibliotecários deve contemplar um aporte 
teórico e prático que os habilite a explorar com competência todos esses segmentos, sempre com a visão de que os serviços, produtos e sistemas possuem - ou deveriam - o enfoque no atendimento às demandas sociais, técnicas e científicas de usuários.

Nesse mesmo sentido, as relatoras das Diretrizes Curriculares Nacionais dos Cursos de Filosofia, História, Geografia, Serviço Social, Comunicação Social, Ciências Sociais, Letras, Biblioteconomia, Arquivologia e Museologia, Durham, Weber e Figueiredo (2001), tratando especificamente da Biblioteconomia, definiram que os conteúdos de formação específica, como aqueles relacionados, entre outros, com as Tecnologias de Informação, não devem ser enfatizados em detrimento da "[...] adoção de uma perspectiva humanística [...]”, de tal forma que fosse resguardado "[...] um sentido social e cultural que ultrapasse os aspectos utilitários mais imediatos sugeridos por determinados itens".

É difícil não enveredar por esse olhar mais aplicado de formação profissional que enfatize mais as tecnologias que os conteúdos, numa sociedade que é bombardeada por informações sobre os avanços tecnológicos e perspectivas de desenvolvimento como, por exemplo, o do periódico Carta Capital de 19 de janeiro de 2005, cuja reportagem de capa (Lobo, 2005) tratou dos avanços tecnológicos em diversas áreas - nanotecnologia, genética, neuromarketing, realidade virtual -, para os quais a humanidade está investindo recursos e esforços de pesquisa. Como possíveis fatos portadores de futuro, essa gama de opções deve estar no centro das atenções daqueles que são responsáveis pelo ensino e pesquisa em ciência da informação, alterando as perspectivas e as projeções para uma carreira que igualmente deve estar preparada para mediar informação em ambientes mutantes, densos e complexos.

Outro documento, que tem por objetivo imaginar o futuro das tecnologias de informação em 2051, apresenta uma tabela contendo suposições acerca de ocorrências relativas ao desenvolvimento tecnológico que vão desde a utilização de votação eletrônica sobre questões de administração pública na cidade de São Paulo, que ocorrerá em 2007, à venda de um robô "empregado doméstico" cujo recorde de venda está previsto para o ano de 2040 (AMARAVADI, 2003).

Então, conforme tratado anteriormente, todos esses pontos têm interface com informação e sua organização, com formação profissional e mediação. Além disso, no aspecto mais humano desses temas, não se deve esquecer que a construção da noção de cidadania é fundamentada no acesso e acessibilidade à informação, do mesmo modo que a ciência prospera com maior facilidade onde a informação é mais bem organizada e acessível.

Assim, levantar esses pressupostos que parecem tão longínquos da realidade atual, bem como identificar os pontos de convergência entre questões aparentemente tão díspares 
têm total relação com a formação do profissional da informação, especialmente os bibliotecários, e seu campo de atuação. Como balizador de qualquer planejamento estratégico, a identificação de cenários é um princípio fundamental para minimizar riscos e incertezas na gestão de currículos. Se a tecnologia se desenvolve, ela o faz a partir de pontos teóricos relativamente utópicos, cujos experimentos e suposições são testados nas empresas de pesquisa, nas universidades e nas organizações que precisam sobreviver nesse ambiente competitivo. Por outro lado, é preciso identificar os impactos que essas tecnologias causam nas pessoas, que podem ser beneficiárias ou vítimas de um mundo tão tecnicista.

Alguns textos já apresentavam essa preocupação, como, por exemplo, Hastings e Tennant (1996) que reconheciam que ambientes digitais requeriam bibliotecários "digitais", no sentido de profissionais aptos não apenas a lidar com as tecnologias, mas também conscientes das diferenças de trabalho em ambientes considerados mais tradicionais, citando como exemplo o desenvolvimento de coleções digitais que requer outros conceitos, abordagens diferenciadas em relação a acesso, uso, preservação, prestação de serviços, oferta de produtos, entre outros pontos.

Assim, reforça-se a idéia da importância que tem a competência dos profissionais para igualmente saberem adaptar as ferramentas às necessidades dos diferentes segmentos socioeconômicos existentes em qualquer país, inclusive o Brasil, e para atuarem em contextos diversos. E, de todo modo, não se pode desconhecer que a tecnologia pode significar não apenas mudança de paradigma ocupacional, mas também de desemprego.

O estudo feito por Baptista (2004) de um eixo específico, que é a Internet, como potencial mercado de trabalho para o profissional da informação, embora reconheça que a tecnologia desemprega, sim, aponta que as ofertas de trabalho ampliar-se-ão consideravelmente, mas desvinculadas do emprego, em seu sentido tradicional. Segundo ela, o que está ocorrendo é uma transformação do trabalho e do mercado de trabalho. No caso específico, uma vertente de atuação seria exatamente o da organização da informação no ambiente da rede. Mas para isso é preciso conhecer, saber, ou pelo menos estar preparado para trabalhar de forma eficiente com as tecnologias e também com os conteúdos, de forma integrada e direcionada ao atendimento dos requisitos dos usuários/clientes.

A dissertação de Feitosa (1999) apresenta um estudo centrado no ensino e aplicação de tecnologias de informação nos cursos de Biblioteconomia do Brasil. Por intermédio de suas questões, o pesquisador identificou vários pontos que: visavam à identificação da introdução de conteúdos efetivamente voltados para as tecnologias de informação; a forma de ministrálos; o conhecimento, pelo corpo docente, das inovações tecnológicas; a atualidade da infra- 
estrutura de equipamentos disponíveis nos laboratórios; a utilização de tecnologias de informação como recursos didáticos; e, ainda, quanto as tecnologias de informação estavam efetivamente inseridas em matérias que dependem desses recursos, como, por exemplo, atendimento de usuários, recuperação de informação, entre outras. Suas conclusões, embora com a ressalva de que não foram ouvidos os profissionais em atuação no mercado e nem alunos, é de que a importância dessas matérias é estratégica para inserção e competição no mercado de trabalho, que os professores não estavam efetivamente preparados para ministrar as disciplinas e de que a postura dos docentes ainda é mais de usuários que de "exploradores" dos recursos tecnológicos.

Mesmo considerando que esse não é um trabalho recente, as dificuldades de renovação de quadros e a diminuição dos recursos para treinamento de professores nas Universidades brasileiras merece ser analisado para identificar se, efetivamente, essa situação está diferente.

Os estudos desenvolvidos pela Associação Brasileira de Educação em Ciência da Informação - ABECIN (2001, 2002), relativas ao processo de formação de profissionais da informação são bastante abrangentes em termos de diretrizes, mas enfocam pontos estratégicos na concepção dos currículos e que incluem questões como a necessidade de adequar as proposições ao contexto, aos valores da sociedade no qual os cursos de graduação estão inseridos, assim como reforça que o projeto pedagógico dos cursos reflete a construção de sua identidade, que em última instância refletir-se-á na identidade profissional dos egressos dos cursos.

Da mesma forma que a discussão sobre a formação dos bibliotecários não é objeto de preocupação apenas de países em desenvolvimento como o Brasil, o impacto das tecnologias de informação no exercício profissional é percebido como fator de preocupação e mudança no exterior.

Plosker (2003), relatando o debate ocorrido em painel sobre a Revolução da Indústria da Informação, identificou alguns impactos no exercício profissional dos bibliotecários, com a facilidade de busca e obtenção de informação na web, especialmente a partir do Google. Mesmo reconhecendo a maior independência dos usuários na busca e acesso à informação, o autor reforça, entretanto, que a inexistência de controles de qualidade das informações, o descompromisso com a perenidade dos dados e informações disponíveis e a maior superficialidade dos dados obtidos são itens relevantes que devem integrar qualquer análise dessa relação. Para Plosker, esse distanciamento dos usuários guarda maior relação com outros fatores, como, por exemplo, a falha de marketing e de comunicação na transmissão dos valores que permeiam as bibliotecas, os recursos disponíveis e os bibliotecários na mediação 
de informação. Adiante, no mesmo artigo, Plosker relata, ainda, que os bibliotecários de referência percebem a web como facilitadora de seu trabalho, especialmente no atendimento de usuários não especializados com questões mais amplas e genéricas. Mas que se requer preparo para atuar nesse mundo tecnológico.

Em artigo que trata desse tema, quanto saber manipular de tecnologia, Childers (2003) define três níveis de aprendizado que seriam:

- Nível 1 - Básico: incluindo itens bastante primários de manipulação do equipamento; procedimentos de pesquisa utilizando browsers; segurança de para a questão de vírus; utilização de correspondência eletrônica e, finalmente, navegação nos sistemas;

- Nível 2 - Desejável: incluindo os mesmos itens do nível básico, mas aprofundando em todos eles e incluindo operações mais sofisticadas;

- Nível 3 - Alvo: que seria o nível desejável ainda mais aprofundado.

Pela descrição dos níveis e pelo público alvo identificado no texto, que compreende o staff de bibliotecas, depreende-se que o conhecimento ainda é bastante incipiente, considerando-se que os dados de identificação de necessidades de treinamento foram de 2003. E não parece que essa tabela possa ser generalizada nem mesmo no Brasil, país considerando entre os que detêm índices de exclusão digital bastante expressivos. Mas a idéia principal não é o quanto cada nível aprofunda, mas a mensagem parece clara: o trabalho nas áreas de informação mudou decorrente das tecnologias de informação, então, há que se estar aparelhado para trafegar nele com competência e utilizando as habilidades normalmente reconhecidas nos profissionais da informação que são: capacidade de tratar, organizar, "empacotar" e fornecer informação.

\section{CONCLUSÕES}

A literatura que trata da formação profissional dos bibliotecários e arquivistas costuma ter um tom alarmista e catastrófico de alerta para os perigos de não saber lidar com as tecnologias de informação sob pena e risco de sucumbirem por desinteresse do mercado. Paralelamente discute-se, nessa linha de análise da atuação profissional, a concorrência de outros perfis, especialmente daqueles de formação básica em informática.

Por outro lado, da leitura dos textos de tecnologia da informação aplicada depara-se com um mar de soluções e de perspectivas quase ilimitadas para todas as questões reais e 
potenciais. Os problemas e equívocos para a organização, muitas vezes desastrosos, sob todos os pontos de vista, somente são tratados de maneira teórica, apenas no sentido de alerta, quase nunca apresentando os casos reais de erros colossais de adoção equivocada de soluções tecnológicas.

No meio desse leque de opções entre a catástrofe e o éden é que provavelmente se situa a realidade de formação profissional e de uso e conhecimento das tecnologias de informação. O complexo, nesse caso, é dimensionar exatamente quanto se deve conhecer, no caso dos profissionais da informação, especialmente os bibliotecários, considerando a gama de aplicativos e aplicações, soluções e serviços disponíveis ou potenciais.

É utópico imaginar que os cursos de graduação, de mestrado, ou de doutorado conseguirão responder a essas demandas de forma absoluta. Por outro lado, migrar a formação para cunhos mais tecnológicos pode incorrer em superposição com cursos como ciência da computação, que têm outro enfoque. Encontrar esse equilíbrio é um desafio para as Universidades que ainda têm que tornar os cursos atraentes para que sejam procurados por sua excelência, por responderem às demandas da sociedade, por proporcionarem uma carreira ampla e reconhecida do ponto de vista social e financeiro. Além disso, deve-se ter o cuidado de demonstrar que as diferenças de perfis com os egressos dos cursos de informática não diminuem sua importância e relevância e que esses deveriam ser complementares, já que não parece justificável para as Universidades, já tão carentes de recursos, investirem em cursos com "produtos" semelhantes.

Parece, como bem explicitou Plosker (2003) que os bibliotecários devem reforçar suas habilidades e características distintivas que incluem: capacidade de síntese e de organização de informação; olhar voltado para as necessidades de informação de usuários; treinamento em procedimentos de recuperação de informação; competências para identificar necessidades e adequar conteúdos, segmentando e especializando respostas em respeito a demandas específicas; compreensão do trabalho com a informação de forma integrada e que, em síntese, realmente diferenciam esses profissionais de outros com perfis limítrofes. Mesmo com deficiências e atrasos em relação ao desenvolvimento científico e tecnológico, que são comuns a todos os cursos, é provável que a sociedade reconheça nas diferenças maiores fatores de sucesso na construção de equipes de desenvolvimento de serviços ou sistemas de informação, senão já haveria tempo para que os cursos fossem considerados obsoletos o bastante para não mais subsistirem no meio acadêmico e no mercado de trabalho.

Ao contrário, se os cursos de graduação estão sendo cada vez mais massacrados do ponto de vista da qualidade de seus egressos, conforme aponta em muitos casos a literatura, os 
cursos de pós-graduação em ciência da informação, mesmo havendo uma tendência tecnicista em seus quadros discentes - exemplo da Universidade de Brasília que constatou que aproximadamente $45 \%$ de seus alunos têm formação de graduação em informática, conforme estudo apresentado pela Prof ${ }^{a}$ Suzana Mueller por ocasião do evento de comemoração dos 25 anos da pós-graduação do Departamento de Ciência da Informação e Documentação da UnB - têm observado um crescimento de procura para submissão aos seus exames para seleção de candidatos.

Isso é absolutamente compatível com o que a literatura tem apontado como tendência das diferentes sociedades de dar maior importância à informação como recurso de fato estratégico.

Não se trata de defender feudos ou mesmo de negar a importância de se conhecer as diversas ferramentas tecnológicas, mas fundamentalmente de dimensionar esse conhecimento de tal forma a não tornar iguais os diversos profissionais, sob risco de perder suas diferenças, que é o que há de mais rico na humanidade. Há que se criar uma ponte sólida o bastante para permitir o tráfego seguro pelas possibilidades das tecnologias, da mesma forma que se deve reforçar a importância dos conteúdos, da organização da informação e do respeito às particularidades das demandas dos usuários, de tal forma que as soluções para as necessidades de informação tenham realmente maior qualidade, utilidade e impacto social.

Sempre é melhor que não sejamos iguais em formação, mas complementares em nossos olhares para que a sociedade, em última instância, seja a maior beneficiária dos diferentes saberes.

\section{REFERÊNCIAS}

ABBOTT, Andrew. The information professions. In: The system of professions: an essay on the division of expert labor. Chicago: University of Chicago Press, 1988. p.215246.

ABECIN. Avaliação do processo formativo na área de Biblioteconomia/Ciência da Informação: documento referencial. In: SEMINÁRIO NACIONAL DE AVALIAÇÃO CURRICULAR, 4., 2002, Fortaleza. Oficina Regional de Trabalho Norte/Nordeste. Fortaleza, 2002. 23p. Disponível em: http://www.abecin.org/Documentosabecin.htm. Acesso em: $8 / 1 / 2005$.

ABECIN/FORGRAD. Projeto pedagógico e avaliação da graduação: referências para a renovação e ressignificação do ensino de Biblioteconomia/Ciência da Informação. In: Oficina Regional de Trabalho de São Paulo. São Paulo, 2001. 29p. (Documentos ABECIN, 1). Disponível em: http://www.abecin.org/Documentosabecin.htm. Acesso em: 8/1/2005. 
AMARAVADI, Chandra S. The world and business computing in 2051. Journal of Strategic Information Systems, v. 12, p. 373-386, 2003.

BAPTISTA, Sofia Galvão. As oportunidades de trabalho existentes na Internet na área de construção de páginas de unidades de informação: discussão sobre idéias divulgadas na literatura. In: ; Mueller, Suzana Pinheiro Machado. (orgs.) Profissional da informação: o espaço de trabalho. Brasília: Thesaurus / CID-UnB, 2004. p.234-241.

BARBOSA, Ricardo Rodrigues. Perspectivas profissionais e educacionais em Biblioteconomia e Ciência da Informação. Ciência da Informação, v. 27, n. 1, p. 53-60, jan./abr. 1998.

BARROS, Fernando Antônio Ferreira de. Os avanços da tecnociência, seus efeitos na sociedade contemporânea e repercussões no contexto brasileiro. In: BAUMGARTEN, Maíra. A era do conhecimento: matrix ou agora? Porto Alegre: Ed. da Universidade Federal do Rio Grande do Sul; Brasília: Ed. UnB, 2001. p.73-87.

BEDNAREK-MICHALSKA, Bozena. Creating a job description for an electronic resources librarian. Library Management, v. 23, n. 8/9, p. 378-383, 2002.

BERTHOLINO, Maria Luzia Fernandes. Dos átomos aos bits: evolução dos suportes da informação. In: RAMOS, Maria Etelvina Madalozzo (org.). Tecnologia e novas formas de gestão em bibliotecas universitárias. Ponta Grossa: Universidade Estadual de Ponta Grossa, 1999. p.183-190.

BIO, Sérgio Rodrigues. Sistemas de informação: um enfoque gerencial. São Paulo: Atlas, 1994.

BLATTMANN, U.; RADOS, G.J.V. Bibliotecários na sociedade da informação: mudança de rótulos, funções ou habilidades? Disponível em: http://www.geocities.com/ublattmann/papers/biblioSl_18.html. Acesso em 22/10/2002. Artigo apresentado no 18. Painel de Biblioteconomia em Santa Catarina, Florianópolis, 22 out. 1999.

BOAR, Bernard. Tecnologia da informação: a arte do planejamento estratégico. 2.ed. São Paulo: Berkeley, 2002. 339p.

BRAUN, Linda W. New roles: a librarian by any name. Library Journal, v. 127, n. 2, p. 4649, Feb. 2002.

CAMPOS, Maria Luiza de Almeida. As cinco leis da Biblioteconomia e o exercício profissional. Disponível em: http://www.conexaorio.com/biti/mluiza/index.htm. Acesso em: $25 / 1 / 2005$.

CASTRO, C.A. História da biblioteconomia brasileira. Brasília: Thesaurus, 2000. 288p.

CHILDERS, Scott. Computer literacy: necessity or buzzword? Information Technology and Libraries, v. 22, n. 3, p.100-104, Sep. 2003. 
DURHAM, Eunice Ribeiro; WEBER, Silke; FIGUEIREDO, Vilma de Mendonça. Diretrizes curriculares nacionais dos cursos de Filosofia, História, Geografia, Serviço Social, Comunicação Social, Ciências Sociais, Letras, Biblioteconomia, Arquivologia e Museologia. Brasília: Ministério da Educação/Conselho Nacional de Educação, 2001. Parecer CNE/CES 492/01, aprovado em 3 de abril de 2001. Disponível em: http://www.proacad.ufpe.br/dde/diretrizes_curriculares/136301fhgslcbam.doc. Acesso em: $8 / 1 / 2005$.

FEITOSA, Ailton Luiz Gonçalves. Formação profissional e tecnologia: estudos sobre o ensino de tecnologias de informação em cursos de Biblioteconomia. Brasília: Universidade de Brasília, 1999. 176p. Dissertação de Mestrado.

GUIMARÃES, José Augusto Chaves. Moderno profissional da informação: elementos para sua formação no Brasil. Transinformação, v.9, n.1, jan./abr. 1997. Disponível em: http://www.puccamp.br/ biblio/guimaraes91.html. Acesso em: 28/10/2002.

GUIMARÃES, José Augusto Chaves. Profissionais da informação: desafios e perspectivas para sua formação. In: BAPTISTA, Sofia Galvão; MUELLER, Suzana Pinheiro Machado. (orgs.) Profissional da informação : o espaço de trabalho. Brasília: Thesaurus / CID-UnB, 2004. p.87-104.

HASTINGS, Kirk; TENNANT, Roy. How to build a digital librarian. D-Lib Magazine, nov. 1996. Disponível em: http://www.dlib.org/dlib/november96/ucb/11hastings.html. Acesso em: 25/5/2004.

HIGOUNET, Charles. História concisa da escrita. São Paulo: Parábola, 2003. 192p.

LOBO, Flávio. O poder se multiplica. Carta Capital, 19/1/2005, p.12-20.

MAN, John. A revolução de Gutenberg: a história de um gênio de uma invenção que mudaram o mundo. Rio de Janeiro: Ediouro, 2004. 318p.

MARCHIORI, P.Z. Bibliotecários, jornalistas e informáticos: a ocupação de posições relativas no campo de atividades de informação. Transinformação, v.8, n.1, jan./abr. 1996. Disponível em: http://www.puccamp.br/ biblio/marchi81.html. Acesso em 31/10/2002.

MUELLER, Suzana Pinheiro Machado. Perfil do bibliotecário, serviços e responsabilidades na área de informação e formação profissional. Revista de Biblioteconomia de Brasília, v. 17, n. 1, p. 63-70, jan./jun. 1989.

ORTEGA Y GASSET, José. EI libro de las misiones. Madrid: Espasa-Calpe, 1965. 162p.

PLOSKER, George R. The information industry revolution: implications for librarians. Online, v.27, n.6, p.16-22, nov./dec. 2003.

SCIENCE DIRECT ONLINE. Disponível em: http://www.periodicos.capes.gov.br/. Consultado em: 10/5/2004. 
SMIT, Johanna W.; BARRETO, Aldo de Albuquerque. Ciência da informação: base conceitual para a formação profissional. In: VALENTIM, Marta Lígia (org.) Formação do profissional da informação. São Paulo: Polis, 2002. p. 9-23.

REZENDE, Denis Alcides. Tecnologia da informação integrada à inteligência empresarial: alinhamento estratégico e análise da prática nas organizações. São Paulo: Atlas, 2002.155p.

TAKAHASHI, Tadao (org.) Sociedade da informação no Brasil: livro verde. Brasília: Ministério da Ciência e Tecnologia, 2000. p.176.

THOMPSON, James. The role of the librarian. In:

librarianship. London: Clive Bingley, 1977. p.102-138.

A history of the principles of

WERNECK, Hamilton. O profissional do século XXI. Rio de Janeiro: Record, 2003. 174p.

\begin{abstract}
The introduction of the information and communication technologies in the labour environment of the information professionals caused changes in the way of working, in the perspectives of the offer of services and products to users, and in the necessities of professional education. This work discusses some difficulties related to the formation of librarians, concerning to the disciplines related to information technologies, and how literature has been discussing this subject. It is also pointed the interface with other professionals and how the distinctive characteristics of the librarians should be warranted so they can compete to information jobs.
\end{abstract}

KEYWORDS: Information professionals. Librarian. Professional education. Information technology.

Agradecimentos: Às professoras Dra ${ }^{\mathrm{a}}$. Marisa Bräscher Basílio Medeiros e Sofia Galvão Baptista pelas orientações e críticas.

Originais recebidos em 22/09/2004. 